\title{
A final problem
}

\section{Beware a sure thing.}

$\mathrm{C}$ anterbury station blinked into crystal reality as I released the red button.

There were two trains at the platform the Continental Express and a one-coach. A bad sign. But to be certain, I checked the screen of the randomization apparatus: "Success probability for this realization: 0." Damn! Immediate action would be required, but despite this urgency I was drawn to an unfamiliar book I held in my left hand. It appeared to be a collection of American witticisms. One passage was highlighted:

Q: How was Thomas J. Watson buried? A: Nine edge, face down.

I did not comprehend ... was this Watson a relative of John's? And what is a 'nine edge'? Given my immediate danger, there was no time for further thought. American humour, I shrugged mentally. Impenetrable.

Moriarty rounded the station house, revolver drawn. I press the randomizer's red button.

Dover station appeared. Again two trains. The apparatus screen again read "Success probability for this realization: 0". A new and again unfamiliar book was in my left hand, written by a fellow I had never heard of S. Hawking. One line was highlighted:

... theoretical physics is ... all in the mind.

I had no time to puzzle over this: the professor was upon me and took aim. I press the red button.

Canterbury station appeared anew. Still two trains. The screen still read "Success probability for this realization: 0". A different book was in my left hand, apparently a collection of aphorisms. One line was highlighted:

At a great bargain, pause a while.

Cryptic, I thought angrily. But no time to ponder: the professor had his revolver

\section{$\rightarrow$ NATURE.COM}

Follow Futures: y @NatureFutures f go.nature.com/ mtoodm levelled at me. I press the red button.

Dover. Canterbury. Canterbury. Dover. Canterbury.
Canterbury. Canterbury. Same result each time: always the same two trains, always Moriarty there with pistol drawn, always the apparatus reporting success probability zero. Each time, however, the randomizer snatched me away at the last moment.

I became uneasy. It seemed improbable to have such a long sequence of failures. I was fleeing and Moriarty was pursuing, each of us on a separate train. If we both get off at the same station - Dover or Canterbury - he would shoot me and I would die. But if we get off at different stations, I escape. The apparatus is my deliverer; with each press of the button it randomly picks a possible world - one realization of all my possible histories. I just need to keep using it until I find a realization where I escape. Then I would live and all other possible histories would collapse into nothingness, never to have been.

Moriarty aims his revolver at me. I press the red button.

A greyed-out train station. Neither Dover nor Canterbury, but with attributes of both or perhaps of all train stations everywhere. Two trains, or maybe none, flicker in and out of existence on the tracks. The platform and station house themselves seem foggy, insubstantial, ghost-like. It is all as if in a dream.

I felt queasy and disoriented. Again I held an unfamiliar text in my left hand. It seemed to be a treatise on natural philosophy, but the exact topic was unfamiliar to me. A section was highlighted:

To make quantum mechanical sumover-histories probability computations consistent with observation we must consider states that are seemingly
I looked down at the randomizer. The screen read: "Success probability for this realization: -0.02." I had a terrible thought. Maybe a realization of me has already succeeded in escaping the professor. Maybe the randomizer now can't find any world where I escape. Maybe all alternative histories - my histories! - have collapsed to nothingness, never to have been.

I looked up to see the spectre of Moriarty come around the station house, revolver drawn. I lunged to grapple with him thinking where do ghosts go to die? - just as the professor pulled the trigger.

A. C. DOYLE is a nom de plume. He works at a large laboratory in Southern California where he and his colleagues watch the sky for low (but positive) probability events. 